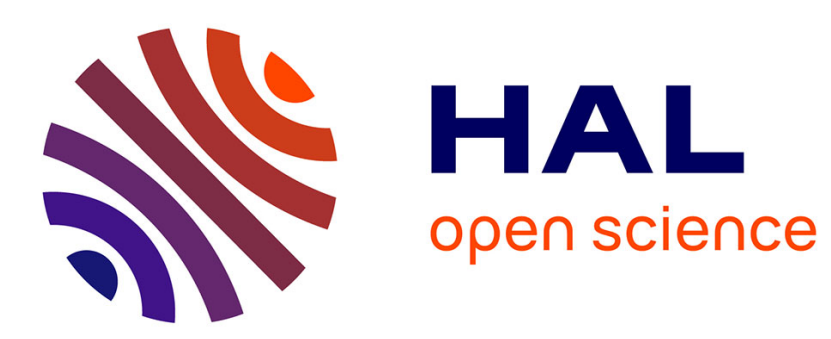

\title{
Changing Markets: Implications for the Planning Process in ETO Companies
}

Kristina Kjersem, Marte F. Giskeødegård

\section{To cite this version:}

Kristina Kjersem, Marte F. Giskeødegård. Changing Markets: Implications for the Planning Process in ETO Companies. IFIP International Conference on Advances in Production Management Systems (APMS), Sep 2019, Austin, TX, United States. pp.554-561, 10.1007/978-3-030-30000-5_68 . hal02419234

\section{HAL Id: hal-02419234 \\ https://hal.inria.fr/hal-02419234}

Submitted on 19 Dec 2019

HAL is a multi-disciplinary open access archive for the deposit and dissemination of scientific research documents, whether they are published or not. The documents may come from teaching and research institutions in France or abroad, or from public or private research centers.
L'archive ouverte pluridisciplinaire HAL, est destinée au dépôt et à la diffusion de documents scientifiques de niveau recherche, publiés ou non, émanant des établissements d'enseignement et de recherche français ou étrangers, des laboratoires publics ou privés. 


\title{
Changing markets: implications for the planning process in ETO companies
}

\author{
Kristina Kjersem $^{1}$ and Marte F. Giskeødegård ${ }^{2}$ \\ ${ }^{1}$ Møreforsking Molde AS, Britvegen 4, 6410 Molde, Norway \\ ${ }^{2}$ NTNU Ålesund, Norway \\ kr i st i na. kj er sem@i mol de. no \\ mart e. gi skeodegar d@it nu. no
}

\begin{abstract}
This article focuses on project planning within an ETO context using shipbuilding as an empirical case. The aim of the research is to understand how a change in market from offshore to cruise affect the planning processes. The article adopts qualitative methods to understand the involved actors strategies and choices to execute a new type of build. The research shows how long-terms association with one market, caused a certain flow of work. This allowed the involved actors to rely on routine activities, which made the actual process of planning fade into the background. A new market comes with new challenges and demands, which disrupted this workflow. The article analyses what caused the lack of focus on planning and its consequences. It argues for a danger of companies confusing structure with content, and calls attention to the importance of the context of planning. In this case, the context of market.
\end{abstract}

Keywords: Project planning, ETO, market change

\section{Introduction}

In a recent research project studying the planning process in Engineer-To-Order (ETO) companies, an interesting observation surfaced during a discussion at a shipbuilding company. One of the participants stated that some years ago, they had invested significant resources in establishing structures to ensure a good planning process, but these seemed to have deteriorated with time. In the following discussion, the participants seemed to agree this was related to a long-term commitment on building ships for one specific market. This approach resulted in developing a certain flow in their work processes, which made the planning process fade into the background. Faced with a new market situation, the company acknowledged that the project planning process seemed poorer and a different focus was necessary if they were to achieve better project management and control. The situation is not unique for this company since many other similar shipbuilders encounter a shift towards other market segments. Following this observation, the main research question in this study is: How does market changes affect the planning process in an ETO environment?

The industrial context of this study is shipbuilding, an industry characterised by ETO strategies. Since the 90's, many Norwegian shipbuilding companies have been 
focused on delivering offshore-specialized vessels (OSV) dedicated to activities within the oil industry. However, low oil prices during the last few years led many shipbuilding companies to adapt to producing new types of vessels, mainly for the cruise market. The significance of this change to new markets, that this research focuses on, is illustrated in Figure 1, [1] that depicts the types of vessels produced by three of the main Norwegian shipbuilding companies between 2010-2016. Out of 160 vessels produced in that period, none of them was a cruise ship or related to the cruise market. The area that is developing fast nowadays is the market for smaller cruise ships that could sail in more demanding environments (e.g. arctic waters). Since these vessels are comparable in size and tonnage with some of the OSVs, most OSV shipbuilders decided to enter the cruise vessels market.

Fig. 1: Types of vessels delivered from 2010 to 2016 [1]

\begin{tabular}{|c|c|c|c|c|c|c|}
\hline \multirow[b]{2}{*}{ Yard } & \multicolumn{2}{|c|}{ Yearly number of ships delivered } & \multicolumn{4}{|c|}{ Ship types } \\
\hline & 2010-2016 & Total & PSVs & AHTSs & Other OSVs ${ }^{1}$ & Other types ${ }^{2}$ \\
\hline $\mathrm{A} 1$ & $3 ; 2 ; 4 ; 2 ; 3 ; 1 ; 3$ & 18 & 10 & 4 & 3 & 1 \\
\hline A2 & $2 ; 1 ; 2 ; 5 ; 4 ; 0 ; 2$ & 16 & 1 & 3 & 8 & 4 \\
\hline A 3 & $4 ; 4 ; 3 ; 4 ; 4 ; 1 ; 0$ & 20 & 18 & 0 & 2 & 0 \\
\hline A4 & $1 ; 3 ; 5 ; 3 ; 3 ; 3 ; 1$ & 19 & 7 & 8 & 4 & 0 \\
\hline A5 & $4 ; 3 ; 3 ; 4 ; 1 ; 1 ; 2$ & 18 & 8 & 1 & 7 & 2 \\
\hline B & $2 ; 4 ; 4 ; 5 ; 2 ; 3 ; 2$ & 22 & 12 & 1 & 8 & 1 \\
\hline $\mathrm{Cl}$ & $5 ; 4 ; 5 ; 5 ; 5 ; 5 ; 3$ & 32 & 11 & 6 & 13 & 2 \\
\hline $\mathrm{C} 2$ & $4 ; 2 ; 2 ; 1 ; 3 ; 2 ; 1$ & 15 & 5 & 2 & 5 & 3 \\
\hline Total & $25 ; 23 ; 28 ; 29 ; 25 ; 16 ; 14$ & 160 & 72 & 25 & 50 & 13 \\
\hline
\end{tabular}

Embarking on such restructuring demands a new type of thinking. While this presents a challenge, some key defining features of the industry speaks positively to their ability to make this transition. According to [1], among this industry's strengths are: 1) Norwegian shipbuilding companies are effectively organized and have long traditions in producing advanced vessels. 2) They count on skilled and multidisciplinary workforce that build its knowledge and experience through generations of seafaring and craftsmanship. 3) Flat and informal organizational structures with short distances between workers and managers, as well high worker autonomy.

A significant change from OSV projects to the cruise market is the primary focus within our project. In most OSV projects, the customers concern with details principally focused on the technical capabilities of the components installed on the vessel. Here the shipbuilders have a certain slack within the decision process. On the cruise projects, the technical part is expected to hold a certain standard, but the focus in the dialog with the shipyard is on the details of the interior, a vital element for customers' competitive edge on this market. This change in focus represents a change concerning which areas of the building process yards are allowed some (if any) slack. The new situation potentially redefines work processes and provides new coordination chal- 
lenges. These changes are necessary to see in relation to the ETO context. In [2], ETO is defined as a production approach where each customer requires significant changes to the fit, form and function of the product so that it meets a specific purpose. This causes a potentially high level of variability from project to project even if, at the surface level, products might seem similar to one another [3]. It is necessary to understand how project planning changes with a shift in market in an ETO context.

\section{Theoretical background}

ETO companies deliver complex multilevel products that often contain parts that are engineered to order [4] challenging the process of delivering exactly the required product. The demand for customized products is increasing and that results in a growing number of ETO companies [5]. Yet, development of theories or paradigms is slower and according to [6], there is a lack of research devoted to this environment. This statement is reinforced by [7], who revealed that literature on product development has been published for decades, while the majority of ETO literature has been published within the last ten years. Thus, our study aims to contribute to the existing literature on ETO and management of such challenging projects.

ETO products are delivered through a project-based approach where planning is an essential activity and most teams apply management ideas from the project management literature. Planning is the process of defining goals and establishing the procedures to accomplish them and becomes effective only when it is intertwined with the process of controlling activity execution [8]. Even though most project managers agree that planning is important for a successful project, the process of planning a is not really understood [9]. According to [10] there are several major flaws of project planning: Focus (scheduling is overemphasized while planning process is neglected). Role (control overshadows action planning). Process (proper decision-making gets all the attention, while the necessary steps prior to the following it are ignored).

In [10] the conclusion is that such traditional project planning approach results in a situation where "instead of the advanced formal planning setting the course of action, it is its execution that shapes the so called formal plan" (p.263) [10]. Furthermore, the PMBOK ${ }^{\circledR}{ }^{1}$, state that the project team should take into consideration the contextual perspective of each project (cultural, social, political, etc.), however, most of the project management literature rarely discuss the project context, or how to act, react or interact within different contexts [11]. Hence, a more effective planning process needs a change in methods, modified strategies, expectations should be adjusted (e.g. attitude to uncertainty) and the overall philosophy of project management should be reconsidered [10]. Through focusing on market shifts, this study will contribute to this call for increased attention to context.

To deal with challenges within the planning process, lean construction community developed a planning tool called Last Planner System (LPS $®$ ) that recommends four planning levels that would function as an arena for communication between project

\footnotetext{
${ }^{1}$ Project Management Body of Knowledge - the guide published by Project Management Institute
} 
participants [12]. The first planning level is the master plan containing milestones and phase durations. The next level is phase scheduling where activities form the previous level become more detailed showing conditions of satisfaction between processes within phases. The third level is the lookahead plan which role is to identify and remove, five to eight weeks in advance, eventual activity constraints so each activities can be completed as planned. The fourth level is week plan where activities are quite detailed and project teams make reliable promises and make sure that activities to be completed in the following two weeks are not constrained. Eventual constraints are dealt with during weekly meetings and measures are taken to solve the problem as soon as possible, and teams affected by delays get the information on time [13].

LPS $®$ has been implemented in many types of project-based industries including shipbuilding. Several Norwegian companies report different approaches to its implementation: some developed a three level plan, others developed only two levels, while a third type used all four recommended levels. However, the main idea is that all these companies use LPS $®$ as a tool to inform project teams about the status of the project activities. While the LPS ${ }^{\circledR}$ recommend a certain planning structure, the issue addressed in the beginning of this paper, turns the attention once again to the importance of context. As a company shifts from one market to another, it might be necessary to make significant changes in regards to the content of this structure (hence, what is focused on). This article aims to contribute to the LPS® literature by drawing attention to the danger of companies confusing planning structure with planning content.

\section{Case company}

During the years producing OSVs, most shipbuilders focused on developing and implementing improvements for many of their working processes with a scope to reduce lead time and total cost of their products. One of these processes was the planning approach to such projects. Our case company designs and builds several types of highly customized vessels for both OSV, fishing, cruise markets, etc. About ten years ago, the company introduced parts of LPS $®$ concept and developed an own structure of their planning process. They adopted four planning levels: project-, lookahead- and week plans, and then assigned a specific type of planning meeting to address each of these levels, that respectively provides information to a certain planning level.

The first level was the project plan meeting where the project manager, dedicated coordinators (purchasing, technical, production) and project planner discussed issues regarding the project status and identified solutions for some of the problems at management level. In addition, some of the key sub-contractors were invited when relevant. The second level was a lookahead planning meeting where discipline coordinators from several technical and production specializations as well as some of the most relevant sub-contractors discussed project issues that needed solutions at this level. The third level was production meetings where own and sub-contractors' team leaders from all disciplines (steel, welding, machinery, etc.) discussed production issues.

These planning structures worked quite well for our case company while producing OSVs. Both central management and head of planning were confident in their ability 
to use such planning structures as a good tool to ensure flow in the work process. Project teams developed a good understanding of their roles and attributes. Coordination of these projects was based on trust and a certain slack within the decision process. A consequence of the positive flow of coordinating these activities was that meeting facilitators seemed to gradually lose focus on the planning aspect, as things were working quite well. It became a background activity performed mostly by the planners. Case in point was the decision to move the planning manager to another department during a fall in the market. This fall led also to layoffs and contract termination for own employees and some of the sub-contractors.

When the company decided to produce vessels for the cruise market, they assumed that most planning structures would remain more or less the same and little attention was given to the processes needed to make them work. All three meetings were now focused more on firefighting and solving problems that the project team was not prepared for. The activities listed in the plan were largely according to the intended meetings in terms of timespan. Yet, in the discussion about coordination issues, activities had to be delayed or even done earlier and people often changed dates in the plan from a qualified guess, which they were prepared to change again if necessary, rather than a real root cause analysis of the situation. Thus, addressing the coming weeks' activities, particularly long-term, was seldom discussed at these meetings. The participants seemed well oriented about each other's activities, and it was clearly a good information flow in the project. The problem was that the plan seemed to stop being most relevant point of reference to know what needed to be done and when. No one seemed to expect that the dates in the plan were accurate and seemed to think that the necessary adjustments were more important to do elsewhere. This lack of confidence in the plan become a self-fulfilling prophecy that can also explain why these meetings turned into an arena for day-to-day coordination more than planning meetings.

When presented with these reflections, the company commented that they appeared to have lost focus on the planning process. A key reason was the previously mentioned slack that had been developed because of similarities between previous projects. Another reason, was that layoffs and retirements in the same period meant that many of the key personnel involved in the work of putting planning on the improvement agenda was gone. Thus, they questioned if this meant that the current project organization did have the same understanding of the philosophy behind the structure of the planning meeting. Although this is a single case study, [14] argues this can be the start of a multiple-case study and in our research we intend to develop a more comprehensive analysis on how similar product categories can affect the planning processes within ETO environment.

\section{Methodology}

The aim of this study is to understand how change in market affect project planning in ETO companies. Qualitative methods are thus best suited, as we need in-depth understanding of the involved actors strategies and choices [14]. The data material consist of data from document analysis and 22 semi-structured interviews with relevant rep- 
resentatives from the case company and its subcontractors. Moreover, the researchers have conducted participant observation of seven project planning meetings at all the levels presented above. The selection of candidates for the interviews has carefully considered different roles and disciplines involved in the project to ensure a complementary picture of the process of building the ship. A snowball method for data gathering has been adopted. Initially, a list of relevant interviewees where drafted. Additional people have been recruited, made relevant from topics that came up in the interviews or through suggestions from the interviewees. Moreover, preliminary findings were discussed with the project steering group on three occasions. The group consist of relevant management from technical, sales and production departments, a key sub-contractor and representatives from two research institutions. Discussing the preliminary findings with this group have further enhanced our understanding of the addressed issues.

\section{$5 \quad$ Findings}

During the interviews done for our research project, one common theme resurface continuously: known, well established processes and procedures are affected by the change of the market. The problem amplified because of the flow that have developed in the work processes and made the company lose track of the planning part of their planning structures. Since this was working, it seems reasonable to assume that these meetings slowly were redefining into long-term and short-term coordination meetings. Thus, the company failed to reassess the current planning process suitability for a new market. There were several signals that necessary adjustments were called for.

OSVs were relatively easier to produce while cruise vessels demand a very different type of thinking that most employees were not aware off. The three types of structures for project meetings functioned well due to aspects like: 1) Project teams have established a mutual understanding of the activities to be executed and everybody knew when these could be done. 2) Customers trusted shipyards' expertize and that resulted in a certain amount of slack in regards to the decision process. 3) Most of the sub-contractors have developed long-term relationships with the shipyard and that contributed to a good understanding of the flow within the shipbuilding process. 4) Planning was performed by the shipyard in collaboration with the most relevant subcontractors. Consequently, they achieve a certain level of trust where problems were solved "on the floor" by people involved in the project. Planning meetings were an arena for discussing activities for the next period and measures needed to solved eventual problems. 5) Most coordinators were employees with experience and they were part of the team who developed the three planning structures.

When changing the type of market, the company observed that the three planning structures were challenged in an unexpected way. Among the reasons could be: 1) Activities within cruise projects were much more detailed and the main focus was on the accommodation part as oppose to the technical part as with OSV projects. Thus, the mutual understanding of project activities was challenged and needed a total review. 2) Customers buying cruise vessels have a different approach to collaboration 
and project management. Because most of these customers have never built vessels with these shipbuilders, there is a lack of trust that can only be built over several projects. Consequently, most decisions are discussed at several levels affecting the execution of the planned activities. 3) Many of the sub-contractors used in OSV projects are not prepared to deliver in cruise projects. This implies that the shipyard had to find new sub-contractors meaning that the mutual understanding of the project problems was no longer existing. Moreover, some of these sub-contractors gain more negotiating power if the customer imposed them to the shipyard. 4) Planning was performed by the shipyard, however, through a different collaboration with subcontractors. More focus on contractual issues between the parts resulted in a different collaborating frame. Planning meetings were no longer an arena for preparing the next period activities, but a place to discuss most demanding issues. 5) New coordinators did not get enough training in leading these meetings and even though the old planning structures are still used, their focus is no longer the same.

This article started initially with the observation that a good flow in the work process had caused a lack of focus on the planning process. By good flow, we here refer to a tacit coordination of work tasks, where participants know what to do, and what others are meant to do, as a result of having worked together on several similar projects. In our case, the argument can be made that good flow shifts the understanding of such meetings from planning to short- and long-term coordination. This becomes problematic because one can lose sight of the strategic potential of evaluation planning structure when the context of work changes. The situation shed light on a real dilemma: good planning can be a very important requisite to facilitate good workflow, but when one achieves good workflow, it can become harder to keep focus on the importance of the content of planning.

\section{Discussion}

The case presented here is another confirmation of the need for more effective planning methods as argued by [10] and to adapt project management approach to the context of the project as argued by [11]. It also sheds light on the fact that planning needs to take into consideration the relationship between the work processes that have changed from one type of project to another while the structure remained the same. One might think that using the same employees and the same type of thinking, the planning process can be performed in the same way.

The purpose of this paper is twofolded and brings to attention the importance of adapting the planning process to the context of the project. For the practitioners, the findings presented above shows that projects need different approach to planning when embarking on unfamiliar markets and that needs to be established before the start of the project. Using LPS ${ }^{\circledR}$ is an approach that can improve the planning process, however, ETO companies need to continually adopt its structures to the context and the specific challenges within each project. Moreover, planning meetings should address planning issues and include real root cause analysis for the encountered problems. For the theoretical contribution, this paper brings into discussion the need for 
developing better understanding of the project planning process in ETO environment. The case presented her is not unique. We have had several projects within similar companies and planning challenges remain a constant issue.

\section{$7 \quad$ References}

1. Semini, M., et al., Offshoring Strategies in Norwegian Ship Production Journal of Ship Production and Design, 2018. 34(1): p. 59-71.

2. Sharpe, G., D. Smith, and P. Knight, White paper: Meeting the needs of "Engineer to Order" Businesses with Jobscope Enterprise ERP, I.g.B. Solutions, Editor. 2015: www.in2grate.com.

3. Haartveit, D.G., M. Semini, and E. Alfnes, Integration Alternatives for Ship Designers and Shipyards, in Advances in Production Management Systems. Value Networks: Innovation, Technologies, and Management, J. Frick and B. Laugen, Editors. 2012, Springer Berlin Heidelberg. p. 309-316.

4. Hicks, C., D. Song, and C. Earl, Dynamic scheduling for complex engineer-to-order products. International Journal of Production Research, 2007. 45(15): p. 3477-3503.

5. Cutler, T.R., Are you ETO? The increasing Importance of Custom (Engineer-to-Order) Manufacturers 2005, TRCluter.Inc. : InMFG. p. 1-3.

6. Gosling, J., M.M. Naim, and D. Towill, A supply chain flexibility framework for engineer-to-order systems. Production Planning \& Control, 2013a. 24(7): p. 552-566.

7. Willner, O., et al. Globally Distributed Engineering Processes: Making the Distinction between Engineer-to-order and Make-to-order. in 47th CIRP Conference on Manufacturing Systems. 2014. Windsor, Ontario Canada.

8. Wiendahl, H.-H., G. Von Cieminski, and H.-P. Wiendahl, Stumbling blocks of PPC: Towards the holistic configuration of PPC systems International Journal of Production Planning \& Control: The Management of Operations, 2005. 16(7): p. 634-651.

9. De Reyck, B., Effective Project Planning: Making the Most of Project Planning Tools. Production and Inventory Management, 2010. 46(2): p. 10-25.

10. Laufer, A. and R.L. Tucker, Is construction project planning really doing its job? A critical examination of focus, role and process. Construction Management and Economics, 1987. 5: p. 243-266.

11. Bosch-Rekveldt, M., Managing project complexity: A study into adapting early project phases to improve project performance in large engineering projects. 2011, Delft University of Technology. p. 336.

12. Ballard, G. and I.D. Tommelein, Current Process Benchmark for the Last Planner System 2016, University of California, Berkeley USA.

13. Ballard, G. If you can't say "no", you can't make a promise. in Seminario Internacional de Confibilidade da Petrobras. 2014. Brasilia, Brazil

14. Yin, R.K., Case Study Research: Design and Methods 5th ed. 2014, USA: Sage Publications, Inc. . 